and importance, and, from the ophthalmologist's point of view, have usually done so in a very inadequate fashion.

For the establishment of the maximum degree of efficiency in the Army, Navy and Air Services, in the re-organisation of industry which is likely to take place after the War, and in connection with the proposed establishment of a Ministry of Health, numerous ophthalmological questions will arise.

It has been suggested that an authoritative and representative Council of British ophthalmologists should be formed to advise and assist Government departments and other public bodies as to suitable standards of vision for different occupations, as to measures for the preservation and welfare of the eyesight of the community, and in any other matters in which the knowledge and experience of ophthalmologists will be of special service.

To bring about the formation of such a Council it is proposed that a meeting shall be held at the Royal Society of Medicine, 1 , Wimpole Street, W., on Thursday, May 2nd, at 6 p.m,, immediately after the Annual Meeting of the Ophthalmological Society. All British ophthalmologists are invited to attend.

The first resolution to be proposed at this meeting will be :-

"That a representative Council of British ophthalmologists be formed to supervise matters of ophthalmological interest arising in connection with public affairs."

If this resolution is carried, the constitution of the Council will then be considered. It is suggested that it should consist of three classes of members: (a) Permanent; (b) Annually selected ; (c) Co-opted.

(a) The permanent members to be the present and past Presidents of the Ophthalmological Society of the United Kingdom and of the Section of Ophthalmology of the Royal Society of Medicine.

(b) The annually selected members to be nominated in equal numbers by the Councils of the Ophthalmological Society of the United Kingdom and the Section of Ophthalmology.

(c) The Council so formed to be granted power to co-opt other members for special purposes.

$$
\text { We are, Sir, }
$$

Yours faithfully,

ANDERSon Critchett,

JOHN TWEEDY,

Priestley Smith,

GEORGE A. BERRY,
J. B. LAWFORD,

F. RICHARDSON CROSS,

WM. LANG,

E. Treacher Collins.

\title{
School Lighting
}

There seems to be some hope of the important subject of education receiving some measure of attention on a more scientific 
plan than has been the case.in the past. The question of the satisfactory lighting of schools is one of the greatest importance both from the point of view of the prevention of what is known as school myopia, and also for the removal of strain and hence loss of efficiency in normal sighted children. We have just received an advance copy of a new code of lighting school buildings issued in New York by the Illuminating Engineering Society. We are not aware of the existence of any similar published code in this country. Such a code would be of great assistance both in designing new buildings and in the improvement of the lighting conditions in old ones. In the hope that some useful discussion of the recommendations given by the American Society may follow we give the following summary :

“1. Intensity of artificial illumination.

Minimum foot candles per square foot

\begin{tabular}{lcccccl} 
Storage spaces & $\ldots$ & $\ldots$ & $\ldots$ & $\ldots$ & $\ldots$ & 0.25 \\
Stairways, corridors & $\ldots$ & $\ldots$ & $\ldots$ & $\ldots$ & $\ldots$ & 0.5 \\
Gymnasiums ... & $\ldots$ & $\ldots$ & $\ldots$ & $\ldots$ & $\ldots$ & 1.0 \\
Rough shop work & $\ldots$ & $\ldots$ & $\ldots$ & $\ldots$ & $\ldots$ & 1.25 \\
Auditoriums, assembly rooms & $\ldots$ & $\ldots$ & $\ldots$ & 1.5 \\
\multicolumn{6}{l}{ Class rooms, study rooms, laboratories, } \\
Fine shop work \\
Sewing, drafting rooms
\end{tabular}

“2. Lamps should be suitably shaded to minimize glare. Glare, either from lamps or from unduly bright reflecting surfaces, produces eye-strain.

" 3. Lamps should be so arranged as to secure a good distribution of light on the work, avoiding objectionable shadows and sharp contrasts of intensities.

" 4. Walls should have a moderate reflection factor; the preferred colours are light gray, light buff, dark cream and light olive green. Ceilings and -friezes should have a high reflection factor; the preferred colours are white and light cream. Walls, desk-tops, and other woodwork should have a dull finish.

“5. Emergency lighting should be provided at main stairways and exits to ensure reliable operation when, through accident or other cause, the regular lighting is extinguished.

" 6 . All parts of the lighting system should be properly maintained to prevent deterioration due to dirt accumulation, burned out lamps and other causes."

When daylight is used it is recommended that the minimum intensities should be considerably greater than those provided in artificial lighting, owing to the adaptation of the eye to a much higher level of illumination in the daytime. If the room does not exceed 20 feet in width, the best result will be obtained from 
windows about 10 feet high on one side. If the rooms are much wider than this, windows must be provided on two sides, preferably the left and rear. The window area should not fall below 20 per cent. of the floor area when windows are located on two sides of a room, and not below 25 per cent. when on one side only. Suggestions as to control of daylight by shades are given, with illustrations of types of screen found satisfactory in actual working.

Photographs illustrating good and bad lighting systems with advice as to the improvement of the latter are given, as also methods of calculating the illuminating value of various systems of lighting. The pamphlet merits the serious consideration of all connected with the designing and maintenance of school and other educational buildings.

\section{Ophthalmia neonatorum}

We have drawn attention in these columns (December, 1917, p. 756), to the advisability of making provision in large towns for the collective treatment of cases of ophthalmia neonatorum, and to the steps taken in the desired direction under the impetus afforded by the recent Report of the Departmental Committee on the Welfare of the Blind. It will be recalled that the Local Government Board asked the Metropolitan Asylums Board to make provision for the hospital treatment of certain cases of the disease. We learn with satisfaction that the latter body has purchased for the sum of $£ 22,553$ from St. Pancras Union, St. Margaret's Home and adjacent freehold property in Kentish Town for the purpose in question, and that later the Board will establish a similar hospital south of the Thames. Questions of transport, the non-separation of mother from baby, the necessity of skilled attention as regards the recently confined mother, and the provision of a physician skilled in the care of infants, must be dealt with by the responsible authority.

\section{Head-Surgery Units}

From a communication in the Ophthalmic Record of October last by Dr. Casey Wood, we gather that the Surgeon-General of the United States Army, has created a special section in Surgery of the Head, divided into ophthalmology, oto-laryngology, brain surgery, and the plastic surgery of the face and head. This section is under the general direction of Lieut.-Col. T. C. Lyster, of the SurgeonGeneral's office, with whom are associated the following, forming a sub-committee of the General Medical Board of the Council of National Defence: Major Nelson M. Black (ophthalmology), Major H. P. Mosher (oto-laryngology), Major V. P. Blair (oral and plastic surgery), and Captain Charles Bagley, junior. Some of the best known specialists throughout the country have been commissioned by this committee and assigned to various cantonment and other 